\title{
LEMBAGA KEKHALIFAHAN SEBAGAI SATU INSTITUSI POLITIK
}

\author{
Achmad Room Fitrianto \\ Fakultas Syariah Institut Agama Islam Negeri (IAIN)Sunan Ampel. Jalan A. Yani 117 Surabaya
}

\section{Abstract}

The issue of leadership succession has always been an interesting issue of all time. Beside the emergence of the issue of succession and power struggles, the problems of empowering the people and sustaining the civilization are also one of the keys of power transitions. One of the most widely known leadership succession in history is the successions that happened after the death of the Prophet Muhammad saw. This episode was responded variously by many parties of that time. However, Abu Bakar as. came up with an awareness that the death of the Prophet Muhammad saw was not the end of anything. There is a huge responsibility to continue the islamic civilization that has been built by the Prophet Muhammad saw. Therefore, the caliphate system was developed and established. At the time of Umar as, the caliphate system was enhanced with the establishment of the Shura Council. Dynamic development of the caliphate system has become an interesting study recently. The system was built based on the divine prophetic system. It was then adopted into a system that puts its main concerns for the society. After some time, the system was degraded by the worldly interests of the Umayyad family who turned it into a monarchy system. However, the development of this system 
through periods can be analyze in order to gain some valuable lessons for the modern leaderships.

Key words: caliphate, leadership succession, politics

\section{Pendahuluan}

Dakwah Muhammad SAW saat pertama kali dikumandangkan, tidak terlepas dari konstelasi politik pada saat itu, baik secara regional maupun internasional. Kekuatan Binzantium (Romawi) maupun Sasanid (Persia) pada saat itu merupakan dua imperium super power yang sangat berkuasa di zamannya. Pada tahun 603-628, terjadi perseteruan besar-besaran dua kekaisaran ini yang menguras habis kekuatan keduanya, namun demikian mereka masih bisa melangsungkan pemerintahannya dengan tetap saling bermusuhan, dengan menggandeng para suku badui Arab sebagai sekutunya hingga tegaknya pemerintahan kaum muslimin.

Perseteruan bahwa kekaisaran tersebut direkam dalam al Quran dalam surat al Rum. Pada tahun 622, Heraklius menyerang kekaisaran Sasanid melalui dataran tinggi Armenia. Menjelang tahun 625 yaitu tahun terjadinya perang Uhud, penguasa Byzantium ini siap membuat serbuan penuh ke jantung kekaisaran Sasanid. Pada tahun 828 ia benar-benar berhasil mengalahkan kekaisaran Persia dan memaksa orang-orang Sasanid untuk kembali pada status quo sebelumnya (Hodgson, 2002: 180; Spluer, 1995: 5).

Posisi Makkah yang berada tepat pada jantung Arab, pertengahan antara Syiria dan Yaman, menjadikannya sebagai tempat yang strategis. Para sejarawan membagi semenanjung Arab menjadi tiga bagian, yaitu Arabia Felix, Arabia Patraea dan Arabia Deserta, yang menghubungkan tripartit kekuasaan. Pada awal abad Kristen, Arabia Felix adalah daerah yang merdeka, Arabia Patraea di bawah kekuasaan Roma dan Arabia Deserta di bawah kekuasaan Parthia (Hitti, 1970: 44). Makkah terletak di antara Arabia Deserta dan Arabia Felix. Daerah Arabia Felix menghubungkan daerah subur di Arabia Felix dan daerah padang pasir di sekitar Mesopotamia, sehingga acapkali menjadi rebutan pengaruh antar dua kekaisaran tersebut di tanah Arab. Akan tetapi, para suku Badui Arab sekitarnya menghendaki daerah ini sebagai daerah yang netral. Sikap para suku yang berdiam di Arab ini terekam dalam buku Hodgson yang berjudul The Venture Of Islam: 223, bahwa: "Tugas utama orang-orang Quraisy atas nama dirinya sendiri atau juga atas nama suku- 
suku sekutunya adalah mempertahankan kemerdekaan wilayah mereka. Baik orang-orang Romawi maupun Abisine telah melakukan sejumlah ekspedisi ke wilayah itu”, “...melerai mereka dari kekuasaan Abisine atau Sasand atau juga Byzantium dan menyekutukan mereka dengan kota-kota perdagangan Hijaz".

Pada saat itu Muhammad SAW mendakwahkan ajaran al Quran dan berhasil mendirikan negara Madinah dengan menghimpun dan menyatukan beberapa suku dalam satu sistem administrasi pemerintahan. Pasca pemerintahan nubuwah, sistem ini dilanjutkan dengan sistem ke-khilafahan. Akan tetapi tulisan ini dibatasi pada pemerintahan Yazid Bin Muawiyah.

Terdapat tiga alasan mengapa tulisan ini memandang kelembagaan kekhilafahan hanya bisa dinilai sebelum zaman Muawiyah, di antaranya: pertama, Muawiyah dan keluarganya pada awal dakwah Muhammad adalah penentang utama dan baru beriman ketika penaklukkan Makkah; kedua, Muawiyah dalam memperoleh kekuasaannya dengan cara "menjual" al Quran pada perang Siffin, dengan mengacung-acungkan mushaf pada ujung tombak; ketiga, Muawiyah mengingkari kesepakatan dengan Hasan setelah massanya akan dikembalikan ke majelis syura' untuk pemilihan Khalifah (Audah, 2003: 226).

\section{Masa Abu Bakar}

Istilah Khalifah ini muncul ketika masa Abu Bakar dibaiat oleh Umar ketika para sahabat saling berdebat siapa yang paling berhak menggantikan Rasulullah yang wafat. Pembaiatan tersebut diikuti oleh kaum muslimin, pada saat itu di mana maknanya adalah mutawaakilun posisi Rasul. Pemutawaakilan, ini bisa dimaknai dengan melembagakan pola kepemimpinan Rasulullah dan diteruskan di bawah pengayoman orang-orang terdekat dengannya, yaitu kaum muslimin awal (Hodgson, 2002: 289).

Langkah ini diambil karena sesaat setelah wafatnya Muhammad pada 8 Juni 632, terdapat kegundahan dari kalangan sahabat, sampai-sampai Umar r.a menghunus pedang dan berkata; "Barang siapa yang mengatakan Muhammad mati, dia akan mati dengan pedang ini”, namun Umar langsung melunak setelah Abu Bakar membacakan surat ali Imron: 144 yang artinya:

"Muhammad itu tidak lain hanyalah seorang rasul, sungguh telah berlalu sebelumnya beberapa orang rasul [234]. Apakah jika dia wafat atau dibunuh kamu berbalik ke belakang (murtad)? barangsiapa yang berbalik ke belakang, 
maka ia tidak dapat mendatangkan mudharat kepada Allah sedikitpun, dan Allah akan memberi balasan kepada orang-orang yang bersyukur".

Kegundahan masyarakat saat itu suatu yang wajar, karena pada saat itu Muhammad berhasil membangun pola pikir yang terarah sehingga menjadi arus utama sistem religius, artistik, intelektual dan komersial di ranah Arab. $\mathrm{Hal}$ ini dikarenakan telah terjadi peningkatan kesetiaan kultural yang melebihi kesetiaan kultural dari daerah Nil ke daerah Oksus. Peningkatan kesetiaan kultural ini salah satunya adalah karena dakwah Muhammad yang menyentuh seluruh aspek kehidupan di ranah Arab. Dengan kata lain, dapat disimpulkan bahwa Muhammad menjadi patron utama tatanan masyarakat pada saat itu yang melebihi ikatan kultural sebelumnya.

Proses pemilihan pimpinan pasca wafatnya Rasulullah, muncul dua kubu besar untuk memimpin masyarakat Islam. Pertama, dari golongan Muhajirin dengan latar belakang kultural lebih condong kepada masyarakat Arab, dengan mencalonkan Abu Bakar. Kedua, masyarakat Anshar yang secara kultural lebih dekat dengan masyarakat Yaman. Kelompok ini memunculkan calon yaitu Sa'ad Bin Ubadah dari suku Khazraj.

Pembaiatan Abu Bakar ini tidak ada yang mempertentangkan karena pembaiatan ini mengedepankan senioritas, keloyalan dan prestasi kerja di antara para sahabat. Beberapa hal yang menjadi titik poin yang bisa diambil pelajaran adalah: pertama, Abu Bakar terpilih secara demokratis dari semua perwakilan kelompok masyarakat yang ada. Kedua, terbukanya ruang publik untuk berpartisipasi dalam pemilihan. Ketiga, adanya kontrak sosial dengan masyarakat (dalam bentuk baiat) sehingga bisa menunjukkan kesiapan untuk memimpin dan kesiapan untuk di-kontrol.

Langkah pertama yang dilakukan khalifah Abu Bakar setelah dibaiat menjadi khalifah pertama adalah meneruskan pesan Nabi kepada Usamah Bin Zaid untuk memimpin pasukan ke Mu'tah. Tujuan pengiriman pasukan ini adalah untuk menghadang pasukan Romawi yang selalu me-ngancam muslimin dan kewibawaan Madinah (Audah, 2003: 171). Pemerintahan khalifah Abu Bakar yang hanya dua tahun memerintah, memiliki misi untuk memantapkan pemerintahan dengan memerangi suku Badui Arab yang tidak mengakui pemerintahan Madinah pasca meninggalnya Rasulullah. Contoh peperangan tersebut di antaranya, perang melawan Musailamah Al Kadzab yang menghimpun beberapa suku di Yaman, Yamamah dan Oman. Awal provokasi yang dilancarkan oleh Musailamah adalah dengan 
tidak mau membayar zakat ke Madinah (Hitti, 1970: 141).

Lebih dari itu, Musailamah juga memproklamirkan diri sebagai Nabi. Ia kemudian membuat persekutuan antara paham yang dikembangkannya dengan beberapa komunitas yang menentang Islam seperti Sajah, seorang penganut Kristen yang mengaku dirinya sebagai Nabi dan ahli spiritual dari Bani Tamin. Persekutuan ini terlihat semakin kental, semenjak Musailamah menikahi Sajah, hingga memegang kendali 40.000 orang (Hitti, 1970: 141). Perang pada zaman Abu Bakar ini disebut perang riddah (perang melawan kemurtadan). Khalid Ibnu Al Walid sebagai jenderal utama perang ini (Yatim, 2004: 35). Cara ini merupakan tahapan stabilisasi umat Islam pasca meninggalnya Rasulullah, guna memantapkan kepemimpinan Madinah dalam sebuah masyarakat tunggal, di mana seluruh Arab dipersatukan (The Witness-Pioneer International, 2002: Online).

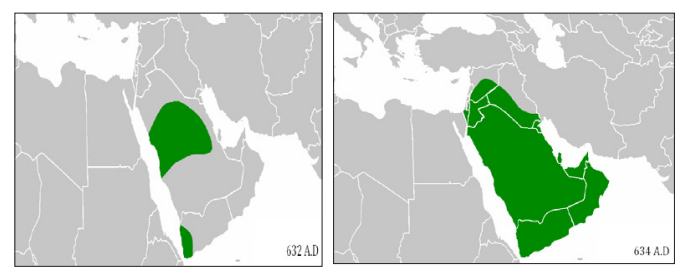

Gambar 13. Perbandingan Wilayah Pemerintahan Islam di Zaman Rasulullah dan Abu Bakar. Sumber: Disarikan dari berbagai sumber (Spuler, 1995; Hitti, 1970).

\section{Masa Umar Ibnu Al Khaththab}

Pada tanggal 22 Agustus 634 Abu Bakar meninggal. Sebelum meninggal, beliau berwasiat agar Umar Ibnu Al Khaththab menggantikannya dengan beberapa alasan. Ali Audah menyebutkan bahwa sebelum menunjuk Umar sebagai penggantinya, sambil berbaring di tempat tidurnya karena sakit, Abu Bakar memanggil Abdurrahman Bin Auf untuk dimintai pendapatnya tentang Umar bahwa beliau memiliki sifat yang keras, namun lemah lembut dan menghormati orang lain. Umar adalah sosok penasehat dan pengontrol dari Abu Bakar, ketika Abu Bakar bersikap terlalu keras, Umar yang menasehati agar melunak, begitu juga sebaliknya jika terlalu lembut Umar menasehati agar lebih keras menghadapinya. Umar juga dikenal memiliki pikiran yang cerdas, tegas, berpegang teguh pada kebenaran dan keadilan (Audah, 2003: 186-188).

Pemilihan Umar yang demikian ini tentu ada yang pro dan kontra. 
Namun dengan kearifan Abu Bakar yang didukung Abdurrahman Bin Auf mampu meyakinkan para sahabat atas penunjukan Umar.

Proses penunjukan ini merupakan paket yang dinilai adil pada saat itu, di antaranya dengan pertimbangan: pertama, peranan penting Umar di saat-saat genting, ketika Umar bisa memberi solusi yang terbaik. Kedua, Umar dalam track recordnya menunjukkan mampu memberikan pertimbangan-pertimbangan cerdas baik selama masa Muhammad SAW maupun semasa Abu Bakar. Ketiga, Umar merupakan orang yang mampu memberikan pertimbangan rasional apabila ada dua pendapat yang berbeda, di sini dikarenakan Umar adalah variabel yang independent (tidak tergantung pada apapun).

Masa pemerintahan Umar berbeda dengan masa Abu Bakar yang disibukkan untuk rekonsiliasi kembali pasca meninggalnya Rasulullah. Profil Abu Bakar sebagai khalifah dikenal sebagai wakil atau pengganti Muhammad SAW. Sedangkan Umar tergambarkan sebagai penerus sistem kekhilafahan. Pada masa Umar, selain istilah khalifah juga dikenal istilah lain bagi kepala negara yaitu Amir Al Mu'min. Dari istilah inilah memunculkan satu komando sistem pemerintahan. Kewenangannya sama dengan struktur wewenang komando militer. Pada masa Umar, struktur pemerintahan dibangun lebih terstruktur dan terperinci, dengan tetap berpedoman kepada al Quran dan apa saja yang ditunjukkan oleh Nabi Muhammad SAW.

Meskipun pola pemerintahan Umar terstruktur dengan garis komando yang jelas dan cenderung militeristik, namun hubungan garis komando didasarkan pada posisi Umar sebagai pemimpin religius maupun milter. Pendekatan ini didasarkan pada hubungan interpersonal, seperti yang dilakukan oleh Muhammad SAW.

Gebrakan yang dibuat Umar dalam sistem pemerintahan adalah terbentuknya Majelis Syuro'. Majelis ini dibentuk guna mempersiapkan proses suksesi kepemimpinan. Menariknya pembentukan majelis ini diawali dengan peristiwa penikaman Umar ketika akan memimpin sholat subuh. Penikaman ini dilakukan oleh Abu Lu'lu'ah Fairuz yang tidak puas menyusul pengaduan dirinya atas perlakuan majikannya yang diajukan kepada Umar. Peristiwa penikaman ini terjadi pada tanggal 2 November 644 dan pada keesokan harinya Umar wafat (Audah, 2003: 191-192).

Majelis Syura' ini beranggotakan enam orang yaitu Usman bin Affan, Ali bin Abi Thalib, Zubair bin Awwan, Thalha bin Ubaidillah, Abdur 
Rahman bin Auf dan Sa'ad bin Abi Waqas tanpa menyebutkan nama calon khalifah. Majelis Syura' bermusyawarah dan akhirnya menghasilkan kesepakatan, khalifah pengganti Umar yaitu Usman bin Affan.

Selain pembentukan majelis syura, ada 45 inovasi yang dibuat Umar yang terekam oleh Abu Hilal Al 'Askari's dalam Kitab al Awa'il ("Buku pertama") dan Tabari's Tarikh (Askari's, 2007: 23). Dalam tulisan ini hanya mencantumkan 16 inovasi yang berkaitan dengan restrukturisasi institusi kekhalifaan sebagai institusi politik.

Table 1. Inovasi Umar Ibnu Khattab Menurut Abu Hilal Al Askari's

\begin{tabular}{|c|c|c|c|}
\hline 1. & $\begin{array}{l}\text { Mendirikan Bayt al Mal } \\
\text { sebagai kas negara }\end{array}$ & & $\begin{array}{l}\text { Mendirikan lembaga peradilan dan } \\
\text { mengangkat hakim }\end{array}$ \\
\hline 3. & $\begin{array}{l}\text { Menggunakan gelar } \\
\text { kenegaraan Amir al Mu'minin }\end{array}$ & & $\begin{array}{l}\text { Mengkoordinir angkatan perang } \\
\text { dalam satu struktur komando }\end{array}$ \\
\hline 5. & Menggaji para tentara & & $\begin{array}{l}\text { Mendirikan lembaga pemungut pajak } \\
\text { atas tanah }\end{array}$ \\
\hline 7. & $\begin{array}{l}\text { Membagi bagian negara ke } \\
\text { dalam beberapa provinsi }\end{array}$ & 8. & $\begin{array}{l}\text { Pajak atas hasil laut dan insentif bagi } \\
\text { petugasnya }\end{array}$ \\
\hline 9. & Membangun struktur penjara & 10. & $\begin{array}{l}\text { Membudayakan Turba (turun ke } \\
\text { bawah) untuk mengetahui kondisi } \\
\text { rakyat }\end{array}$ \\
\hline 11. & $\begin{array}{l}\text { Membangun struktur } \\
\text { kepolisian }\end{array}$ & 12. & Membangun struktur barak tentara \\
\hline 13. & $\begin{array}{l}\text { Melarang perbudakan di } \\
\text { dunia Arab }\end{array}$ & 14. & Memfomulasikan hukum qiyas \\
\hline 15. & $\begin{array}{l}\text { Memperjelas hukum waris } \\
\text { dan pembagiannya }\end{array}$ & 16. & $\begin{array}{l}\text { Membangun sekolah dan memberikan } \\
\text { tunjangan biaya bagi pengajarnya }\end{array}$ \\
\hline
\end{tabular}

\section{Masa Usman Bin Affan}

Pada masa pemilihan khalifah ketiga ini, semangat kesukuan mulai menyeruak muncul. Terbentuknya majelis syura', memotivasi beberapa golongan untuk menguasai majelis. Banyak kekuatan non majelis (kalau sekarang kekuatan non parlementer) yang saling berebut pengaruh. Di antaranya yaitu Abbas bin Abdul Muthalib dari Bani Hasyim dan Abu Sufyan bin Harb dari Bani Umayah. Namun demikian, keanggotaan Ali 
dan Usman dalam majelis bukan untuk mengkompromikan friksi ini. Keanggotaan kedua sahabat tersebut didasarkan pada pemahaman khalifah kedua, bahwa keenam orang ini adalah orang-orang yang dididik oleh Rasulullah SAW secara langsung dari awal dakwah Islam.

Banyak pertentangan yang muncul dalam penentuan khalifah ketiga, namun Abdurahman bin Auf dapat menengahi pertentangan yang muncul dengan bijaksana. Dengan mengerucutnya kandidat khalifah kepada Ali dan Usman, Abdurrahman bin Auf melakukan wawancara secara mendalam kepada keduanya. Lebih lanjut, anggota majelis yang lain juga melakukan public hearing (Audah, 2003: 201). Dari mekanisme yang dilakukan majelis syura' dan atas kebesaran hati Ali bin Abi Thalib maka terpilihlah Usman sebagai khalifah ketiga.

Pada masa Usman kondisi politik diperparah dengan menyusupnya Yahudi, Abdulla bin Saba' yang menjadi provokator dan menyebar yang berakhir dengan terbunuhnya Usman pada 17 juni 656, tepat 12 tahun masa pemerintahan. Setelah kematian Usman, ketegangan masyarakat muslim lebih ruwet daripada masa pemerintahan sebelumnya.

Namun demikian, meskipun masa pemerintahan Usman banyak terjadi gejolak yang mengakibatkan instabilitas politik, pemerintahan Usman memberikan kontribusi terhadap sistem kenegaraan modern dan sistem pendidikan. Di antara buktinya adalah bahwa disusunlah polisi keamanan dan memusatkan kegiatan kemahkamahan dan pengadilan dalam satu bangunan khusy. Pada masa sebelumnya yakni masa Abu Bakar dan Umar bin Khatab, biasanya pengadilan suatu perkara digelar di masjid. Kebijakan strategis dalam pengembangan sumber daya manusia yang dilakukan Usman adalah memperbaiki sistem baku al Quran yang menjadi pedoman utama sistematika pendidikan berbangsa dan bernegara tatanan yang diwarisi dari Rasulullah SAW.

\section{Masa Ali Bin Abi Thalib}

Proses terpilihnya Ali diawali dari bergolaknya periode Usman yang memunculkan banyak ketidakpuasan. Pasca terbunuhnya Usman tidak ada nama lain yang populer selain Ali termasuk Muawiyah sekalipun (Audah, 2003: 218). Pada saat Ali dibaiat oleh para sahabat, banyak dari keluarga Umayah yang tidak mau membaiat Ali dan sebagian pergi ke Syria.

Pada masa pemerintahannya, Ali mengambil kebijakan politik sebagai 
berikut: pertama, resufle pejabat setingkat gubernur di antaranya Ya'la bin Ummayah dengan Abaidullah bin Abbas di Yaman, Abdullah bin Amir Al Hadrami digantikan oleh Utman bin Hunaif untuk daerah Basrah dan beberapa daerah lainnya termasuk Kuffa, dan Syam. Kedua, mengambil tanah yang telah dibagikan Usman kepada keluarganya dan kerabatnya tanpa alasan yang benar. Ketiga, memberikan kepada kaum muslimin tunjangan yang diambil dari Baitul Mal, seperti yang dilakukan Abu Bakar. Keempat, mengatur tata laksana pemerintahan untuk mengembalikan kepentingan umat. Kelima, meninggalkan Madinah dan menjadikan Kufa sebagai pusat pemerintahan (Azra, 2000: 112).

Kebijakan yang diambil tersebut menimbulkan ketidaksenangan khususnya dari keluarga Bani Ummayah (keluarga Usman), di antaranya gubernur Syam yaitu Muawiyah bin Abu Sufyan. Ketidaksenangan ini menimbulkan subordinasi dan berkembang menjadi perseteruan secara terang-terangan antara Bani Hasyim dan Bani Umayah. Perseteruan ini pada akhirnya berujung pada perang Siffin. Perang saudara ini secara politik dimenangkan oleh Muawiyah dengan muslihat Amr bin Ash. Kemenangan ini terasa lengkap dengan terbunuhnya Ali oleh kelompok Khawarij pada tanggal 24 Januari 661 atau tepat pada 17 Ramadhan $40 \mathrm{H}$.

\section{Peralihan Masa Pemerintahan Ali ke Muawiyah}

Dengan adanya perang dingin yang dimenangkan oleh Muawiyah Ibnu Sufyan, walaupun dengan cara yang tidak adil dan bijaksana, menjadikan Muawiyah sebagai tokoh sentral pada saat itu. Subordinasi yang dilakukan oleh Muawiyah ini adalah akibat ketidakpuasan terhadap kebijakan Ali yang mengganti gubernur- gubernur yang diangkat oleh Usman. Subordinasi ini berujung bentrokan antara pasukan yang setia kepada Ali dan Muawiyah yang kemudian dinamakan perang Sifin.

Dalam perang Sifin, kelompok Muawiyah hampir kalah. Tetapi dengan kecerdikannya, Muawiyah menyuruh anak buahnya untuk mengangkat mushaf di atas pucuk lembing, dan meminta agar peperangan dihentikan dan diadakan arbitrase (tahkim). Awalnya Ali tidak menyetujui adanya tahkim, tetapi dari pasukan Ali ada yang meminta untuk menyetujui, sehingga akhirnya dengan berat hati tahkim itu diterima (Shidiqi, 1992: 138).

Pada peristiwa tahkim tersebut, Ali mengutus Abu Musa al As'ari dan Muawiyah mengutus Amr bin Ash sebagai delegasi. Dalam perjalanan 
tahkim tersebut Abu Musa memutuskan bahwa antara Ali dan Muawiyah sama-sama tidak pantas sebagai khalifah, tetapi Amr bin Ash berbicara bahwa yang pantas menjadi khalifah adalah Muawiyah. Dengan adanya tahkim ini, umat Islam mulai pecah menjadi tiga golongan, yaitu Syiah, Muawiyah dan Khawarij.

\section{Masa Awal Pemerintahan Dinasti Umayah}

Pasca tebunuhnya Ali dan menjadikan Muawiyah sebagai sentral tokoh politik saat itu merupakan titik awal perubahan sistem pemerintahan. Dari pemerintahan yang bersifat demokratis yang dibangun sejak zaman Abu Bakar yang telah diletakkan dasar-dasarnya oleh Rasulullah berubah menjadi monarchiheridetis. Suksesi kepemimpinan secara turun-temurun di mulai ketika Muawiyah mewajibkan seluruh rakyatnya untuk menyatakan setia terhadap anaknya, Yazid. Kritikan dilakukan oleh banyak kalangan ketika Yazid ditunjuk oleh Muawiyah sebagai penggantinya. Muawiyah dinilai tidak mentaati isi perjanjiannya dengan Hasan Ibnu Ali ketika naik tahta, yang menyebutkan bahwa persoalan penggantian pemimpin setelah Muawiyah diserahkan kepada pemilihan umat Islam (Yatim, 1993: 45). Penunjukan Yazid sebagai putra mahkota menyebabkan munculnya gerakan-gerakan yang menentangnya. Sebagai akibat dari pertentangan ini memunculkan perang saudara beberapa kali dan berkelanjutan, yang diawali tahun 680 yang dipimpin oleh Husein Ibnu Ali dan berakhir dengan terbunuhnya Husein di Karbela.

\section{Simpulan}

Politiksasi kelembagaan kekhilafahan memang tidak terlepas dari sejarah masa lalu bangsa pada umumnya terutama suku bangsa Quraisy. Masa lalu pemeritahan Qurays tidak terlepas dari persaingan antara Bani Hasyim dan Bani Umayah. Akan tetapi perseteruan ini bisa diminimalisir dan disatukan oleh Muhammad SAW. Al quran dijadikan dasar untuk membangun satu kekuatan yang sedemikian dahsyat dalam kurun-kurun berikutnya. Hal ini terbuktikan pada masa klasik, tidak ada pasukan invanteri darat yang bisa menghadang lacu pasukan"padang pasir" dalam menguasai dunia. Namun di balik itu semua, tidak terlepas dari peran khulafaur rasyidin, dari masa Abu Bakar yang memiliki fungsi rekonsiliasi, Umar dengan restrukturisasi, 
Usman dengan pemantapan/standardisasi pedoman pendidikan Universal Umat (al Quran) dan Ali, atau suatu proses pergeseran arus politik yang besar, hingga Muawiyah mentradisikan kekhilafahan secara turun-menurun.

\section{Daftar Pustaka}

Ali, K. 2000. Sejarah Islam. Jakarta: Rajawali Press.

Askari's-al, Abu Hilal. Al Awa'il dan Tabari's Tarikh dalam Haddad, G.F. 2007. Zaman Selepas Nabi Khalifah Rashidun. (Online), (http://alhakimbestari.org/pdf/31\%20-20KHALIFAH\%20 RASHIDUN.pdf, diakses 24 Juni 2008).

Ash Shidiqi, Hasbi. 1992. Sejarah dan Pengantar Ilmu Tauhid/Kalam. karta: Bulan Bintang.

Audah, Ali. 2003. Ali Bin Abi Thalib, Sampai Kepada Hasan dan Husain. Jakarta: Pustaka Litera AntarNusa.

Azra, Azyumardi. 2000. Ensiklopedi Islam. Jakarta: PT Ichtiar Baru Van Hoeve.

Hitti, Philip K. 1970. History of The Arabs Tenth Edition. New York: Macmillan and Co.

Hodgson, Marshall G.S. 2002. The Venture Of Islam. Terjemahan oleh Mulyadhi Kartanegara. Jakarta: Paramadina.

Kennedy, Hugh. 2001. The Armies of The Caliphs. London: Routledge.

Murodi. 1997. Sejarah Kebudayaan Islam. Semarang: Toha Putera.

Spuler, Bertold. 1995. The Age of The Caliphs. Princeton: Markus Wienner Publishers.

The Witness-Pioneer International. 2002. Abu Bakar in History. (online), (http://www.witness-pioneer.org/vil/Articles/companion/20_abu_ Bakar.htm, diakses 24 Juni 2009).

Yatim, Badri. 1993. Sejarah Peradaban Islam. Jakarta: Rajawali Press. 